archives-ouvertes

\title{
Robust Control System Design for Multivariable Plants with Lightly Damped Modes
}

\author{
Dominique Nelson Gruel, Patrick Lanusse, Alain Oustaloup
}

\section{To cite this version:}

Dominique Nelson Gruel, Patrick Lanusse, Alain Oustaloup. Robust Control System Design for Multivariable Plants with Lightly Damped Modes. 2007 ASME/IEEE International Conference on Mechatronic and Embedded Systems and Applications (MESA07), Sep 2007, Las Vegas, United States. pp.1. hal-00204552

\section{HAL Id: hal-00204552 \\ https://hal.archives-ouvertes.fr/hal-00204552}

Submitted on 27 Dec 2019

HAL is a multi-disciplinary open access archive for the deposit and dissemination of scientific research documents, whether they are published or not. The documents may come from teaching and research institutions in France or abroad, or from public or private research centers.
L'archive ouverte pluridisciplinaire HAL, est destinée au dépôt et à la diffusion de documents scientifiques de niveau recherche, publiés ou non, émanant des établissements d'enseignement et de recherche français ou étrangers, des laboratoires publics ou privés. 


\title{
DRAFT: ROBUST CONTROL SYSTEM DESIGN FOR MULTIVARIABLE PLANTSWITH LIGHTLY DAMPED MODES
}

\author{
D. Nelson-Gruel, P. Lanusse, A. Oustaloup, V. Pommier \\ IMS - CNRS UMR 5218 - Bordeaux 1 University - ENSEIRB \\ LAPS Department - 351, cours de la libération Bât A4 -33405 Talence CEDEX -FRANCE \\ Voice: (+33)5.40.00.36.27 - Fax: (+33)5.40.00.66.44 \\ dominique.nelson@ims-bordeaux.fr
}

\begin{abstract}
A robust controller design is proposed for the active suspension system bench-mark problem. The CRONE control system design used is extended to unstable multivariable plants with lightly damped modes and RHP zeros. Decoupling and stabilizing controller $K$, is achieved for the open-loop transfer matrix. Fractional order transfer functions are used to define all the components of the diagonal open-loop transfer matrix, $\beta$. In defining the fractional open-loop transfer function $\beta_{0 i}$ some elements of the plants, $G_{0}$ and its inverse must be considered to achieve the stable controller. Optimisation provides the best fractional open-loop $\beta_{\text {opt }}$. Finally, frequency domain system identification is used to find controller $K=G_{0}^{-1} \beta_{\text {opt. }}$.
\end{abstract}

\section{KEY WORDS}

lightly damped modes, MIMO, CRONE, control system, fractional order system, frequency domain

\section{INTRODUCTION}

The aim of the MIMO (multivariable) CRONE CSD (control system design) is to robustify the closed loop dynamic performance through a robust either damping factor, or a robust resonant peak of control. Fractional differentiation is used to define the optimal open-loop.

Three generations of CRONE control have been developed, successively extending the application field. The MIMO approach used here is based on the third generation of CRONE CSD (Oustaloup et Mathieu, 1999). It permits treating uncertain and unstable square $n \times n$ MIMO plants with RHP (right half plane) zeros and lightly damped modes (resonant frequencies). Section 2 and 3 briefly outlines the extension of the CRONE CSD methodology. Simulation is given in section 4 .

\section{CRONE CONTROL METHODOLOGY AND MIMO SYSTEMS}

The aim of the CRONE CSD is to find a diagonal open-loop transfer matrix whose $n$ elements are fractional order transfer functions. It is parametered to satisfy the four following objectives:

- perfect decoupling for the nominal plant,

- accuracy specifications at low frequencies,

- $\quad$ required nominal stability margins of the closed loops (behaviours around the required cut-off frequencies),

- specifications on the $n$ control efforts at high frequencies.

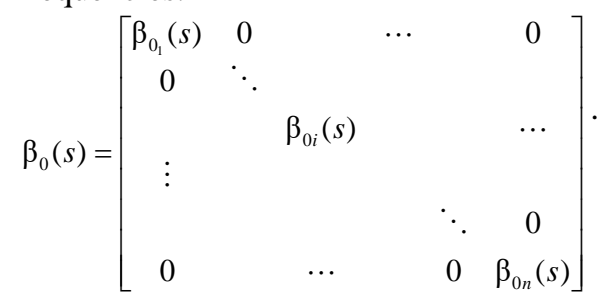

After an optimisation of the diagonal open-loop transfer matrix (1), frequency-domain system identification is carried to obtain the fractional controller. Open-loop transfer functions $\beta_{0 i}(s)$ are used to satisfy the three other objectives.

\subsection{Definition of the diagonal open-loop transfer function elements}

Open-loop transfer function behaviours can be described by using the third generation CRONE CSD methodology presented below. This generation of CRONE CSD uses complex non-integer order integration over a choosen frequency range $\left[\omega_{\mathrm{A}}, \omega_{\mathrm{B}}\right]$. The complex fractional order, 
$n_{\mathrm{f}}=a+\mathrm{i} b$ allows creating a straight line of any direction in the Nichols chart which is called the generalized template figure (1).

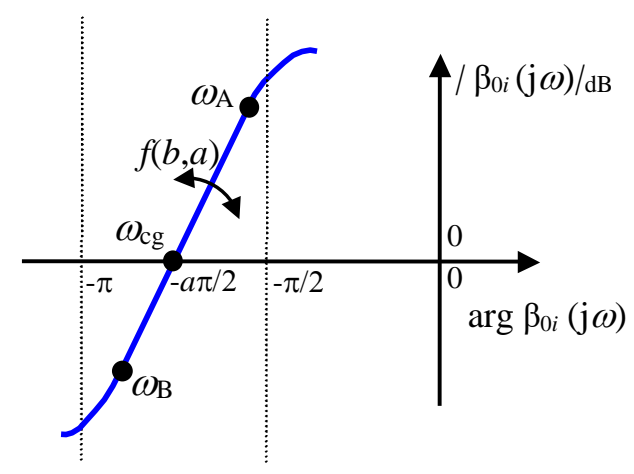

figure 1: Generalized template in the Nichols plane.

The real part of $n_{\mathrm{f}}$ determines its phase location at frequency $\omega_{\mathrm{cg}}$, that is $-\mathfrak{R} e\left(n_{f}\right) \pi / 2$, and the imaginary part determines its direction. The generalized template is described by the limitation in the operational plane $\mathbb{C}_{j}$ of the complex noninteger integrator transfer function:

$$
\beta_{0_{i}}(s)=\left[\left(\frac{\omega_{\mathrm{cg}}}{s}\right)^{n_{\mathrm{f}}}\right]_{\mathrm{C}_{\mathrm{j}}},
$$

with:

$$
\begin{array}{ll}
- & s=\sigma+\mathrm{j} \omega \in \mathbb{C}_{\mathrm{j}}, \\
- & n_{f}=a+\mathrm{i} b \in \mathbb{C}_{\mathrm{i}} .
\end{array}
$$

This transfer function can be described as based on bandlimited complex non-integer integration:

$$
\begin{aligned}
\beta_{0_{i}}(s)=C^{\operatorname{sign}(b)}\left(\frac{1+s / \omega_{\mathrm{h}}}{1+s / \omega_{1}}\right)^{a} & \\
& \times\left(\Re e_{\mathrm{fi}}\left\{\left(C_{\mathrm{g}} \frac{1+s / \omega_{\mathrm{h}}}{1+s / \omega_{1}}\right)^{\mathrm{i} b}\right\}\right)^{-q \operatorname{sign}(b)},
\end{aligned}
$$

with

$$
C=\operatorname{ch}\left[b\left[\arctan \left(\frac{\omega_{\mathrm{cg}}}{\omega_{\mathrm{I}}}\right)-\arctan \left(\frac{\omega_{\mathrm{cg}}}{\omega_{\mathrm{h}}}\right)\right)\right],
$$

and

$$
C_{\mathrm{g}}=\left(\frac{1+\left(\frac{\omega_{\mathrm{cg}}}{\omega_{\mathrm{l}}}\right)^{2}}{1+\left(\frac{\omega_{\mathrm{cg}}}{\omega_{\mathrm{h}}}\right)^{2}}\right)^{1 / 2} .
$$

The corner frequencies are placed around the extreme frequencies $\omega_{\mathrm{A}}$ and $\omega_{\mathrm{B}}$ such that:

$$
\omega_{1}<\omega_{\mathrm{A}}<\omega_{\mathrm{cg}}<\omega_{\mathrm{B}}<\omega_{\mathrm{h}} .
$$

For stable and minimum phase plant the generalized template is taken account in the open-loop transfer function as follows:

$$
\beta_{0_{i}}(s)=\beta_{\mathrm{l}_{i}}(s) \beta_{0_{i}}(s) \beta_{\mathrm{h}_{i}}(s),
$$

with

$$
\beta_{l_{i}}(s)=C_{l_{i}}\left(\frac{\omega_{l_{i}}}{s}+1\right)^{n_{l_{i}}},
$$

the order $n_{l i}$ fixes the accuracy of each closed-loop,

$$
\beta_{\mathrm{h}_{i}}(s)=\frac{C_{\mathrm{h}_{i}}}{\left(\frac{s}{\omega_{\mathrm{h}_{i}}}+1\right)^{n_{\mathrm{h}_{i}}}},
$$

the order $n_{\mathrm{h} i}$ permits the elements of the controller to be proper.

This third generation CRONE control open-loop transfer function has been defined using the gain-crossover open-loop frequency; however this definition can be made using the closed loop resonant frequency too. Then $\omega_{\mathrm{r}}$ replace $\omega_{\mathrm{cg}}$.

\subsection{Decoupling and optimised controller}

Let $G_{0}$ be the nominal plant transfer matrix such that $G_{0}(s)=\left[g_{i j}(s)\right]_{i, j \in N}$ and:

$$
\beta_{0}=G_{0} K=\operatorname{diag}\left[\beta_{0_{i}}\right]=\operatorname{diag}\left[\frac{n_{i}}{d_{i}}\right]_{i \in N},
$$

where:

- $g_{i j}(s)$ is a strictly proper transfer function,

- $\quad N=\{1, \ldots, n\}$,

- $\quad \beta_{0_{i}}=\frac{n_{i}}{d_{i}}$ the element of the ith column and row.

As mentioned above the aim of CRONE control for MIMO plants is to find a decoupling controller for the nominal plant. $G_{0}$ being not diagonal, the problem is to find a decoupling and stabilizing controller $K$ (Vardulkis , 1987). This controller exists if and only if the following hypotheses are true:

$$
\begin{gathered}
H_{1}:\left[G_{0}(s)\right]^{-1} \text { exist , } \\
H_{2}: Z_{+}\left[G_{0}(s)\right] \cap P_{+}\left[G_{0}(s)\right]=0,
\end{gathered}
$$

where $Z_{+}\left[G_{0}(s)\right]$ and $P_{+}\left[G_{0}(s)\right]$ indicate the positive real part zero and pole sets.

The controller $K(s)$ is:

$$
K=G_{0}^{-1} \beta_{0}=\frac{\operatorname{adj}\left(G_{0}\right)}{\left|G_{0}\right|} \operatorname{diag}\left[\frac{n_{i}}{d_{i}}\right]_{i \in N},
$$

with $\operatorname{adj}\left(G_{0}(s)\right)=\left[G_{0}{ }^{i j}(s)\right]^{\mathrm{T}}=\left[G_{0}{ }^{j i}(s)\right], \quad G_{0}{ }^{i j}(s)$ the cofactor corresponding to element $g_{i j}(s)$, and $\left|G_{0}\right|$ corresponding to determinant of $G_{0}(s)$.

Thus:

$$
k_{i j}=\frac{G_{0}^{j i}}{\left|G_{0}\right|} \beta_{0_{i}} \forall i, j \in N .
$$

The nominal sensitivity and the complementary sensitivity transfer function matrices are:

$$
\mathrm{S}_{0}(s)=\left[I+\beta_{0}(s)\right]^{-1}=\operatorname{diag}\left[S_{0 i}(s)\right]_{1 \leq i \leq n},
$$




$$
\mathrm{T}_{0}(s)=\left[I+\beta_{0}(s)\right]^{-1} \beta_{0}(s)=\operatorname{diag}\left[T_{0 i}(s)\right]_{1 \leq i \leq n},
$$

with

$$
\begin{aligned}
T_{0 i}(s) & =\frac{\beta_{0_{i}}(s)}{\left(1+\beta_{0_{i}}(s)\right)}, \\
S_{0 i}(s) & =\frac{1}{\left(1+\beta_{0_{i}}(s)\right)} .
\end{aligned}
$$

For plants other than the nominal, the closed-loop transfer matrices $T(s)$ and $S(s)$ are no longer diagonal. Each diagonal element $T_{i i}(s)$ and $S_{i i}(s)$ could be interpreted as closed loop transfer functions coming from a scalar open-loop transfer function $\beta_{i i}(s)$ called equivalent open-loop transfer function:

$$
\beta_{i i}(s)=\frac{T_{i i}(s)}{1-T_{i i}(s)}=\frac{1-S_{i i}(s)}{S_{i i}(s)} .
$$

For each nominal open-loop $\beta_{0 i}(s)$, many generalized templates can border the same required magnitude-contour of the Nichols chart or the same resonant peak $M_{\mathrm{p}_{0_{i}}}$. The optimal one minimizes the robustness cost function:

$$
J=\sum_{i=1}^{n}\left(M_{\mathrm{p}_{\max _{i}}}-M_{\mathrm{p}_{\min _{i}}}\right)^{2}
$$

where:

$$
\begin{array}{ll}
\text { - } M_{\mathrm{p}_{\max _{i}}}=\max _{G} \sup \left(T_{i i}(\mathrm{j} \omega)\right), \\
\text { - } M_{\mathrm{p}_{\min _{i}}}=\min _{G} \sup \left(T_{i i}(\mathrm{j} \omega)\right),
\end{array}
$$

while respecting the following set of inequalites for $\omega \in \mathrm{R}$ and $i, j \in N$ :

$$
\begin{gathered}
\inf _{G}\left|T_{i j}(\mathrm{j} \omega)\right| \geq T_{i j_{\mathrm{l}}}(\omega), \\
\underset{G}{\sup }\left|T_{i j}(\mathrm{j} \omega)\right| \leq T_{i j_{\mathrm{u}}}(\omega), \\
\sup _{G}\left|S_{i j}(\mathrm{j} \omega)\right| \leq S_{i j_{\mathrm{u}}}(\omega), \\
\sup _{G}\left|K S_{i j}(\mathrm{j} \omega)\right| \leq K S_{i j_{\mathrm{u}}}(\omega), \\
\sup _{G}\left|S G_{i j}(\mathrm{j} \omega)\right| \leq S_{i j_{\mathrm{u}}}(\omega),
\end{gathered}
$$

where $G$ is the nominal and perturbed plant.

As the uncertainties are taken into account by the least conservative method, a non-linear optimization method must be used to find the optimal values of the independent parameters of the fractional open-loop.

\section{CRONE CONTROL DESIGN FOR UNSTABLE MIMO PLANT WITH LIGHTLY DAMPED MODES}

Let the nominal plant transfer matrix $G_{0}$ be:

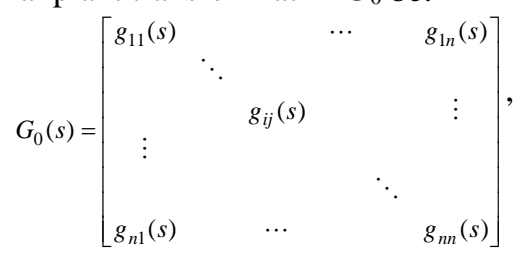

where:

- $\quad g_{i j}(s)=g_{0_{i j}}(s) \cdot h_{i j}(s)$,

- $\quad h_{i j}(s)$ is the transfer including the resonant modes and RHP zeros and poles.

The inverse of $G_{0}$ is:

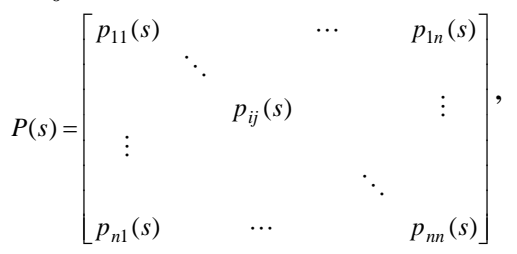

where:

- $\quad p_{i j}(s)=p_{0_{i j}}(s) \cdot m_{i j}(s)$,

- $\quad m_{i j}(s)$ is the transfer function including the resonant modes and RHP zeros and poles.

Thus the controller is:

$$
\begin{aligned}
k_{i j}(s) & =p_{i j}(s) \cdot \beta_{0_{i}}(s), \\
& =p_{0_{i j}}(s) \cdot m_{i j}(s) \cdot \beta_{0_{i}}(s)
\end{aligned}
$$

Now, (31) implies that some RHP zeros, unstable poles, and lightly damped modes of $p_{i j}$ must appear in $\beta_{0 i}$ for the controller to be achievable and stable. The aim of this section is to characterize this open-loop transfer matrix.

\subsection{Lightly damped modes}

Some resonant frequencies must be included in the open-loop transfer function $\beta_{0 i}$ for the controller to be achievable and stable.

The first transfer matrix to consider is the input-disturbance sensitivity, $T_{0} K^{-1}$. Using (10):

$$
T_{0} K^{-1}=S_{0} G_{0}=\left[\frac{d_{i}(s) \cdot g_{0_{i j}}(s) \cdot h_{i j}(s)}{d_{i}(s)+n_{i}(s)}\right]
$$

this transfer function is resonant-free if

$$
d_{i}(s)=\frac{\hat{d}_{i}(s)}{h_{i j}(s)} \forall j \in N .
$$

The denominator of the ith open-loop transfer function must satisfy all the following equations:

$$
\begin{aligned}
d_{i}(s) & =\frac{\hat{d}_{i}(s)}{h_{i 1}(s)} \\
d_{i}(s) & =\frac{\hat{d}_{i}(s)}{h_{i 2}(s)} \\
\vdots & \hat{d}_{i}(s) \\
d_{i}(s) & \frac{h_{i n}(s)}{h^{\prime}}
\end{aligned}
$$

and therefore:

$$
d_{i}(s)=\frac{\hat{d}_{i}(s)}{H_{i}(s)} \quad \forall i \in N,
$$


where, transfer functions $H_{i}(s)$, have in common some lightly damped modes of the ith row of $G_{0}$.

The second transfer matrix to consider is input sensitivity $K S$. Using (10):

$$
K_{0} S=G_{0}^{-1} T=\left[\frac{p_{0_{i j}}(s) \cdot m_{i j}(s) \cdot n_{j}(s)}{d_{j}(s)+n_{j}(s)}\right],
$$

this transfer function is resonant-free if

$$
n_{j}(s)=\frac{n_{j}(s)}{m_{i j}(s)} \forall i \in N
$$

The numerator of the ith open-loop transfer function must satisfy all the following equations:

$$
\begin{aligned}
n_{j}(s) & =\frac{\hat{n}_{j}(s)}{m_{1 j}(s)} \\
n_{j}(s) & =\frac{\hat{n}_{j}(s)}{m_{2 j}(s)} \\
\vdots & \hat{n}_{i}(s) \\
n_{j}(s) & =\frac{m_{n j}(s)}{}
\end{aligned}
$$

and therefore:

$$
n_{j}(s)=\frac{\hat{n}_{j}(s)}{M_{j}(s)} \quad \forall j \in N
$$

where transfer functions $M_{j}(s)$ have in common some lightly damped modes of the $j$ th column of $G_{0}{ }^{-1}$.

Adding some lightly damped modes on the open-loop transfer functions causes resonant frequencies to appear on sensitivity and complementary sensitivity transfer functions. To attenuate their effect, transfer function $Q_{j}(s)$ is included in $\beta_{0 i}(s)$ around each resonant frequency such that:

$$
Q_{j}(s)=\frac{\left(\frac{s}{\omega_{j}}\right)^{2}+2 \xi \frac{s}{\omega_{j}}+1}{\left(\frac{s}{\omega_{j}^{\prime}}\right)^{2}+2 \xi^{\prime} \frac{s}{\omega_{j}^{\prime}}+1},
$$

where:

- $\omega_{j}$ and $\omega_{j}{ }^{\prime}$ are frequencies close to the resonant frequency,

- $\quad \xi$ and $\xi$ are damping factors,

\subsection{Unstable Poles and RHP zeros}

Let $\eta_{z}(a)$ be an integer $\xi$ such that $\lim _{s \rightarrow z} \frac{a(s)}{(s-z)^{\xi}}$ exists and is non-zero (Tao,2005).

So for a given $z$ :

- $\quad a(s)$ has a $\eta_{z}(a)$ order zero at $z$ if $\eta_{z}(a)>0$,

- $\quad a(s)$ has a $\eta_{z}(a)$ order pole at $z$ if $\eta_{z}(a)<0$,

- $a(s)$ has neither pole nor zero if $\eta_{z}(a)=0$.
Inevitably a transfer function is stable and minimum phase if and only if:

$$
\eta_{z}(a)=0 \forall z \in \mathbb{C}^{+}
$$

In our case we need:

$$
\eta_{z}\left(k_{i j}\right) \geq 0 \quad \forall i, j \in N \quad \forall z \in \mathrm{C}^{+}
$$

With (18), (43)becomes:

$$
\eta_{z}\left(k_{i j}\right) \geq \eta_{z}\left(\frac{\left[G_{0}^{j i}\right]}{\left|G_{0}\right|} \beta_{0_{i}}\right)
$$

$\forall i, j \in N \forall z \in \mathbb{C}^{+}$.

Consequently:

$$
\eta_{z}\left(\beta_{0_{i}}\right) \geq \eta_{z}\left(\left|G_{0}\right|\right)-\eta_{z}\left(\left|G_{0}^{j i}\right|\right) .
$$

The ith open-loop transfer function must satisfy all the following equations:

$$
\begin{gathered}
\eta_{z}\left(\beta_{0_{i}}\right) \geq \eta_{z}\left(\left|G_{0}\right|\right)-\eta_{z}\left(\left[G_{0}^{1 i}\right]\right) \\
\eta_{z}\left(\beta_{0_{i}}\right) \geq \eta_{z}\left(\left|G_{0}\right|\right)-\eta_{z}\left(\left[G_{0}^{2 i}\right]\right) \\
\vdots \\
\vdots \\
\eta_{z}\left(\beta_{0_{i}}\right) \geq \eta_{z}\left(\left|G_{0}\right|\right)-\eta_{z}\left(\left[G_{0}^{n i}\right]\right)
\end{gathered}
$$

and therefore:

$$
\eta_{z}\left(\beta_{0_{i}}\right) \geq \eta_{z}\left(\left|G_{0}\right|\right)-\eta_{i}(z) \forall i \in N,
$$

with

$$
\eta_{i}(z)=\min _{j \in N}\left(\eta_{z}\left(G_{0}^{j i}\right)\right) .
$$

Equation (48) shows that the ith open-loop transfer function $\beta_{0 i}(s)$ must have, for each $z$, an $(s-z)$ transfer function at order $\eta_{z}\left(\beta_{0_{i}}\right)$. This order equals the order of $z$ in $\left|G_{0}\right|$ minus the order of $\mathrm{z}$ common to all the elements of the column in $\left[G_{0}^{j i}\right]$. The sign of $\eta_{z}\left(\beta_{0_{i}}\right)$ determines whether the transfer is an RHP-zero or a unstable pole of $\beta_{0 i}(s)$.

Finally, when all the zeros, poles, and lightly damped modes to be include in the ith open-loop transfer function are found:

$$
\beta_{0_{i}}(s)=\beta_{\mathrm{I}_{i}}(s) \beta_{\mathrm{r}_{i}}(s) \beta_{\mathrm{z}_{i}}(s) \beta_{0_{i}}(s) \beta_{p_{i}}(s) \beta_{\mathrm{h}_{i}}(s) \text {, }
$$

with:

$$
\beta_{z_{i}}=C_{z_{i}} \prod_{k=1}^{N_{z_{i}}}\left(z_{i_{k}}-s\right)^{\eta_{z_{i_{k}}}}\left(\beta_{0_{i}}\right)
$$

$$
\begin{gathered}
\beta_{p_{i}}=C_{p_{i}}\left(e^{-\mathrm{j} \pi}\right)^{\Psi} \prod_{p_{i}} \prod_{k=1}^{N_{p_{i}}}\left(\frac{p_{i_{k}}+s}{p_{i_{k}}-s}\right)^{\eta_{p_{i_{k}}}\left(\beta_{0_{i}}\right)}, \\
\beta_{\mathrm{r}_{i}}(s)=C_{r} \frac{H_{i}(s)}{M_{i}(s)} \prod_{j=1}^{\phi} Q_{j}(s)
\end{gathered}
$$

where:

- $\phi$ is the number of lightly damped modes to integrate.

- $\quad z_{i_{k}}$ is a $z$ such that $\eta_{z}\left(\beta_{0_{i}}\right)>0$,

- $\quad p_{i_{k}}$ is a $z$ such that $\eta_{z}\left(\beta_{0_{i}}\right)<0$,

$-\quad \eta_{z_{i_{k}}}\left(\beta_{0_{i}}\right)=\eta_{z}\left(\beta_{0_{i}}\right)$ if $z$ is a zero of $\beta_{0 i}(s)$, 
- $\quad \eta_{p_{i_{k}}}\left(\beta_{0_{i}}\right)=-\eta_{z}\left(\beta_{0_{i}}\right)$ if $z$ is a pole of $\beta_{0 i}(s)$,

- $\quad N_{z_{i}}$ is the number of RHP zeros of $\beta_{0 i}(s)$,

- $\quad N_{p_{i}}$ is the number of RHP poles of $\beta_{0 i}(s)$,

$-\Psi_{p_{i}}=\sum_{k=1}^{N_{p_{i}}} \eta_{p_{i_{k}}}\left(\beta_{0_{i}}\right)$,

- $\quad \Psi_{z_{i}}=\sum_{k=1}^{\mathrm{N}_{z_{i}}} \eta_{z_{i_{k}}}\left(\beta_{0_{i}}\right)$.

In addition, the controller must be proper and permit the rejection of low amplitude disturbances.

Thus using (30), the controller is proper if:

$$
\operatorname{deg}\left(d_{i}(s)\right)+\operatorname{deg}\left(D_{p_{i j}(s)}\right) \geq \operatorname{deg}\left(N_{p_{i j}(s)}\right)+\operatorname{deg}\left(n_{i}(s)\right),
$$

$\forall j \in N$,

with $p_{i j}(s)=\frac{N_{p_{i j}(s)}}{D_{p_{i j}(s)}}$.

As a consequence

$$
\operatorname{deg}\left(d_{i}(s)\right)-\operatorname{deg}\left(n_{i}(s)\right) \geq \max _{j \in N}\left(\operatorname{deg}\left(N_{p_{i j}(s)}\right)-\operatorname{deg}\left(D_{p_{i j}(s)}\right)\right),
$$

and at high frequencies

$$
\operatorname{deg}\left(d_{i}(s)\right)=n_{h_{i}}
$$

and

$$
\operatorname{deg}\left(n_{i}(s)\right)=\Psi_{z_{i}},
$$

gives

$$
n_{h_{i}} \geq \Psi_{z_{i}}+\max _{j \in N}\left(\operatorname{deg}\left(N_{p_{i j}(s)}\right)-\operatorname{deg}\left(D_{p_{i j}(s)}\right)\right) \cdot
$$

At low frequencies, disturbances are rejected if transfer function $S G$ contains no poles at $z=0$ or

$$
\eta_{0}(S(s))+\eta_{0}\left(G_{0}(s)\right) \geq 0 .
$$

and $S(s)$ is equivalent to $\beta_{0 i}(s)$ or

$$
\eta_{0}(S(s)) \approx \eta_{0}\left(\beta_{0_{i}}(s)\right)=n_{l_{i}}+\Psi_{z_{i}} .
$$

Also:

$$
\eta_{0}\left(G_{0}(s)\right)=\eta_{0}\left(N_{g_{i j}(s)}\right)-\eta_{0}\left(D_{g_{i j}(s)}\right),
$$

with:

$$
g_{i j}(s)=\frac{N_{g_{i j}(s)}}{D_{g_{i j}(s)}} .
$$

Therefore:

$$
n_{l_{i}}+\Psi_{z_{i}} \geq \eta_{0}\left(N_{g_{i j}(s)}\right)-\eta_{0}\left(D_{g_{i j}(s)}\right)
$$

$\forall j \in N$.

Finally:

$$
n_{l_{i}} \geq \max _{j \in N}\left(\eta_{0}\left(N_{g_{i j}(s)}\right)-\eta_{0}\left(D_{g_{i j}(s)}\right)\right)-\Psi_{z_{i}} .
$$

\section{APPLICATION}

Consider the widely studied 2x2 active-suspension system (Bao-Tung Lin, 2006, Qing-Guo Wang, 2002 and Reinelt, 2000), given in figure 2 .

$$
\left[\begin{array}{l}
Y_{1}(s) \\
Y_{2}(s)
\end{array}\right]=\left[\begin{array}{cc}
\frac{M_{2} s^{2}+B_{1} s+K_{2}}{\Lambda} & B_{1} s \\
B_{1} s & \frac{M_{1} s^{2}+B_{1} s+K_{1}}{\Lambda}
\end{array}\right] \cdot\left[\begin{array}{c}
U_{1}(s) \\
U_{2}(s)
\end{array}\right],
$$

where:

$$
\begin{aligned}
\Lambda=M_{1} M_{2} s^{4}+ & B_{1}\left(M_{1}+M_{2}\right) s^{3}+\left(M_{1} K_{2}+M_{2} K_{1}\right) s^{2} \\
& +\left(B_{1} K_{2}+K_{1} B_{1}\right) s^{1}+K_{1} K_{2}
\end{aligned}
$$

$M_{1}=1$ and $M_{2}=1.85$ are the two masses; $K_{1}=0.8$ and $K_{2}=1.25$ are the spring elements of the suspension; and $B_{1}=0.8$ is the damper. $K_{2}$ is the uncertain element.

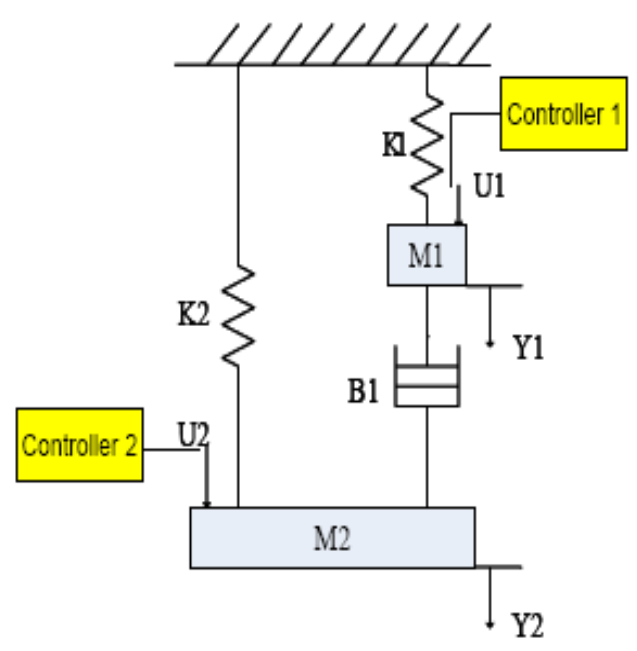

Figure 2: System model

\subsection{Fractional complex definition of the nominal open-loop transfer matrix}

a) RHP zeros, poles and lightly damped modes

The elements to include are:

- $\quad$ an RHP zero at order $\eta_{z=1.25}\left(\beta_{0_{i}}\right)=1$ for both loops at $z=1.25 \mathrm{rad} / \mathrm{s}$.This RHP zero is common to each column of $G_{0}^{-1}$;

- a lightly damped mode at $0.822 \mathrm{rad} / \mathrm{s}$ with a damping factor of 0.263 for the first loop, this mode is common to the first column of $G_{0}{ }^{-1}$.

\section{b) Spécifications}

For all parametric states, the following must be satisfied:

- zero steady-state error for both outputs,

- short as possible settling time,

- perfect decoupling for both loops, 
- first overshoot less than $20 \%$.

With this specification some elements of the open-loop transfer matrix can be initialized. So, with the maximum relative degree of $G_{0}^{-1}(-1)$ and all elements to integrate in the open-loop transfer matrix, $n_{h}$ must be greater than 3 for the first loop, and greater than 1 for the second loop. A zero steady-state error for both loops causes $n_{l}$ to be equal to one. To attenuate the effect of the damped mode and the steady oscillation (figure 3 ) transfer (40) was added to each $\beta_{0_{i}}$

y1
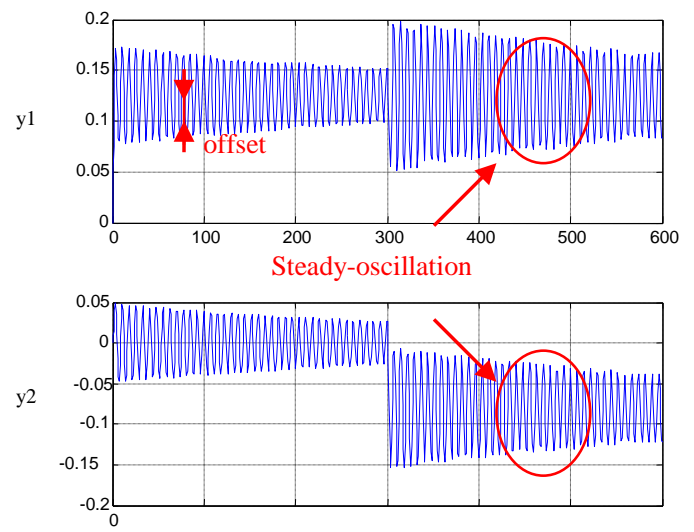

Figure 3: Simulation without feedback

\section{c) Optimisation}

Both open-loop parameter are now to be optimized. For the first loop the initial parameters are :

$$
\begin{aligned}
& -\omega_{\mathrm{r}}=0.05 \mathrm{rad} / \mathrm{s}, \\
& -\quad \omega_{\mathrm{l}}=0.02 \mathrm{rad} / \mathrm{s}, \\
& -\quad \omega_{\mathrm{h}}=0.5 \mathrm{rad} / \mathrm{s}, \\
& -\quad \beta_{0_{1}}(j \omega) \|_{\omega=\omega_{r}}=2 \mathrm{~dB},
\end{aligned}
$$

- $\quad \omega_{n}^{\prime}=\omega_{n}=0.85 \mathrm{rad} / \mathrm{s}, \quad \xi=0.1$ and $\xi=0.8$ for equation (40),

for the second loop:

- $\omega_{\mathrm{r}}=0.02 \mathrm{rad} / \mathrm{s}$,

$-\omega_{\mathrm{l}}=0.005 \mathrm{rad} / \mathrm{s}$,

- $\omega_{\mathrm{h}}=1 \mathrm{rad} / \mathrm{s}$,

- $\left\|\beta_{0_{1}}(j \omega)\right\|_{\omega=\omega_{r}}=8 \mathrm{~dB}$,

- $\omega_{n}=1.2 \mathrm{rad} / \mathrm{s}, \omega_{n}^{\prime}=0.7 \mathrm{rad} / \mathrm{s}, \quad \xi=0.8$ and $\xi^{\prime}=0.6$ for equation (40).

Taking into account all specifications, optimal values for the parameters of each fractional open-loop transfer function $\beta_{0 i}$ are:

- $\quad$ for the first loop: $K=3.6078, a=1.2532, b=-0.4602$, $q=1$ and $C=2.6792$

- for the second loop: $K=18.3767, a=1.3151, b=$ $0.4473, q=2$ and $C=4.1223$

Figure 3 shows equivalent open-loop transfer functions
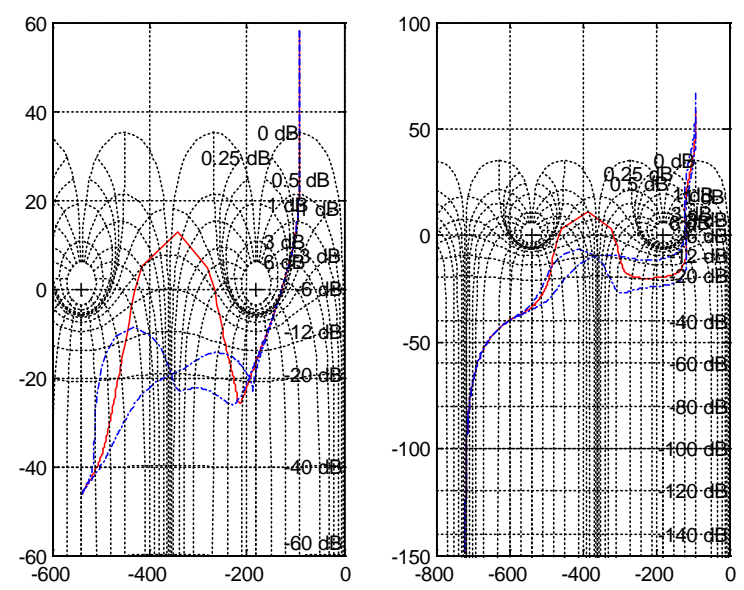

Figure 4: Equivalent open-loop transfer function ((羊羊) nominal, (---) reparametered)

The final controller is found by frequency domain identification

\subsection{Results}

A simulation of the active suspension system is used to evaluate the controller performance. Inputs of the system are unit step and introduced at $t=0 \mathrm{~s}$ (first input), $t=150 \mathrm{~s}$ (second input); disturbances are 0.1 amplitude step and introduced at $t=400 \mathrm{~s}$ (disturbance on the first loop) and $t=600 \mathrm{~s}$ (disturbance on the second loop). The uncertain spring element $K_{2}$ varies between 0.5 and 2. The simulation results are shown in figure 5 for the nominal plant, and figure 6 for nominal and reparametered plants.
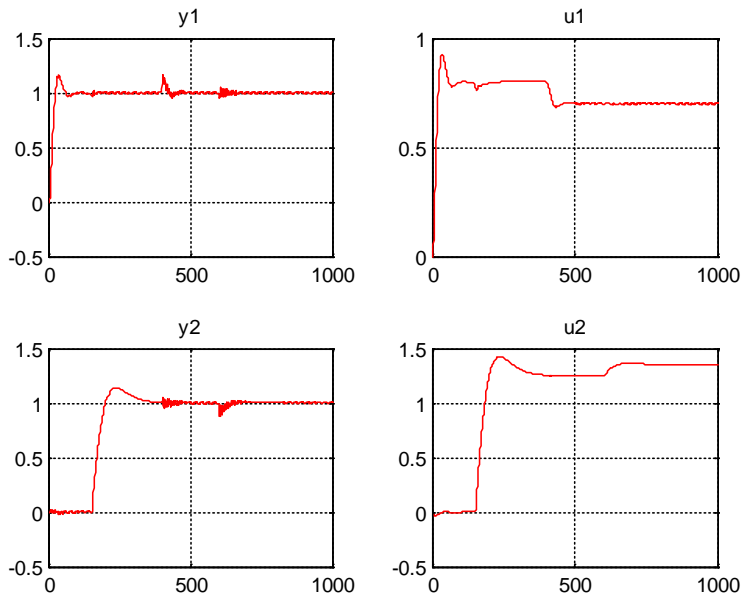

Figure 5 : Control performance of the active suspension system 

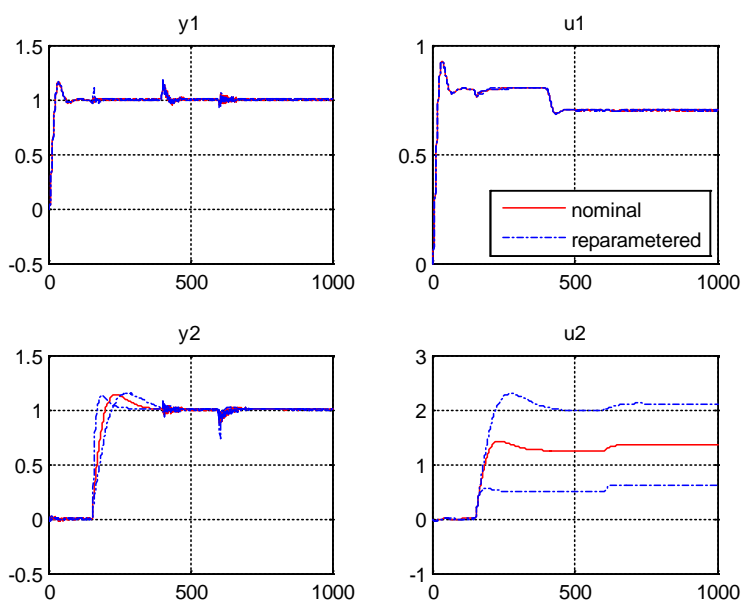

Figure 6 : Control performance of the active suspension system for reparametered state

Figure 5 and 6 show that all specifications are satisfied. Overshoot is almost equal to the imposed limit, but the decoupling specification is satisfied for the nominal plant and preserved for reparametered plants. Also the offset and the steady oscillation have been removed.

\section{CONCLUSION}

The multivariable CRONE approach is based on third generation CRONE control system design. Each open-loop transfer function $\beta_{0 i}$ of the matrix $\beta(s)$ is thus fractional. Frequency domain system identification and linear algebra are used to determine the final controller. For unstable multivariable plants with lightly damped modes and RHP zeros, some RHP poles, RHP zeros, and lightly damped modes of $\mathrm{G}_{0}$ or $\mathrm{G}_{0}^{-1}$ can appear on $K$ or on closed loop transfer matrices. The controller would not be achievable and stable. So a method is therefore proposed for treating this kind of system and to determine a final stable and achievable controller. Adding some RHP zeros, RHP poles, and lightly damped modes in open-loop transfer functions before their optimization render the controller achievable and stable. The method used for the active suspension bench-mark problem. The control obtain is rapid and disturbances rejected.

A crone approach to unstable and non-square multivariable plants with RHP zeros, and lightly damped modes, is being investigated.

\section{REFERENCES}

Bao-Tung Lin, Wen-Nan Huang, Chin-Cheng Teng, «Design of controllers for MIMO active-suspension System Using Combined QFT/ $H_{\infty}$ », 2006 CACS Automatic Control Conference

Oustaloup Alain et Mathieu Benoit, «La commande CRONE», édition Hermes, 1999
Qing-Guo Wang, Yu Zhang, Min-Schen Chiu, «Decoupling internal model control for multivariable systems with multiple time delays», Chemical engineering Sciences, 2002.

Reinelt Wolfgang, «Robust control of a Two-Mass-Spring System subject to its Input Constraints», American Control Conference, Chicago, USA 28-30 June 2000

Spencer Jr B.F., S.J. Dyke and H.S. Deoskar, «Benchmark Problems in structural control Part I: Active Mass Driver System», Proceedings of the 1997 ASCE Structures Congress, Portland, Oregon, April 13-16,1997.

Tao L., W.D. Zhang, D.Y. Gu, «Decoupling control design processes with Time Delays», Acta Automatica Sinica Vol 31 No.6 2005.

Vardulkis A. I. G. - «Internal stabilization and decoupling in linear multivariable systems by unity output feedback compensation», IEEE Trans. on Autom. Control, 32, August, 1987. 